\title{
Review of immunological and virological aspects as contributory factors in Sudden
}

\section{Unexpected Death in Infancy (SUDI)}

\author{
Heleen la Grange ${ }^{a}$ (hlg@sun.ac.za), Janette Verster ${ }^{b}$ (janette.verster@up.ac.za) Johan J Dempers, \\ (id2@sun.ac.za), Corena de Beer ${ }^{\mathrm{a}}$ (deb@sun.ac.za)
}

\begin{abstract}
${ }^{a}$ Division of Medical Virology, Department of Pathology, University of Stellenbosch, P O Box 19063, Tygerberg, 7505, South Africa
\end{abstract}

${ }^{b}$ Department of Forensic Pathology, University of Pretoria, Private Bag X20, Hatfield, Pretoria, 0028, South Africa

'Division of Forensic Pathology, Department of Pathology, University of Stellenbosch, P O Box 19063, Tygerberg, 7505,

South Africa

${ }^{\mathrm{d}}$ Western Cape Forensic Pathology Service, Cape Town, South Africa

Corresponding author: Dr Corena de Beer, Division of Medical Virology, P O Box 19053, Tygerberg, 7505, South Africa. Tel:

+2721938 9453, Fax: +2721938 9361, Email: cdeb@sun.ac.za

\section{Highlights}

- SUDI remains one of the major contributors to infant mortality worldwide

- Viral and bacterial infections are often implicated in these cases

- Histology and laboratory results must agree for a diagnosis of infection

- Different investigation protocols limit comparison of results worldwide

- Bigger studies, sampling of more organs and updating protocols are crucial 


\section{SUMMARY/ABSTRACT}

Currently in South Africa research into sudden unexpected death in infancy (SUDI) is limited. The causes of sudden infant death syndrome (SIDS) remain obscure despite full medico-legal investigations inclusive of autopsy, scene visit and ancillary studies. Viral infections play an important role as a multitude of respiratory viruses have been detected in autopsy specimens and are implicated in these deaths. The specific contribution of viruses in the events preceding SIDS still warrants deciphering. Infancy is characterised by marked vulnerability to infections due to immaturities of the immune system that may only resolve by the age of 24 months. Routine viral screening of all SUDI cases at Tygerberg Forensic Pathology Service (FPS) Mortuary in Cape Town focuses on only a portion of respiratory viruses from lung and liver tissue. This review highlights important virological and immunological aspects regarding investigations into the infectious nature of SUDI, including the lack of national standardised guidelines for appropriate specimen collection at autopsy and subsequent laboratory analysis.

\section{KEY WORDS:}

Sudden infant death syndrome, sudden unexpected death in infancy, Medico-legal investigations, Respiratory immune defence, Respiratory viruses.

\section{LIST OF ABBREVIATIONS:}

C complement

CMV cytomegalovirus

EBV Epstein-Barr virus

FPS Forensic Pathology Service

HAdV human adenovirus 


$\begin{array}{ll}\text { HIV } & \text { human immunodeficiency virus } \\ \text { HMPV } & \text { human metapneumovirus } \\ \text { HPIV } & \text { human parainfluenza virus } \\ \text { HRV } & \text { human rhinovirus } \\ \text { HSV } & \text { herpes simplex virus } \\ \text { IFN } & \text { interferon } \\ \text { Ig } & \text { immunoglobulin } \\ \text { IL } & \text { interleukin } \\ \text { NA } & \text { nucleic acid } \\ \text { RSV } & \text { respiratory syncytial virus } \\ \text { SIDS } & \text { sudden infant death syndrome } \\ \text { SUDI } & \text { sudden unexpected death in infancy } \\ \text { TNF } & \text { tumour necrosis factor }\end{array}$

\section{COMPETING INTERESTS}

The authors declare that they have no competing interests

\section{AUTHORS CONTRIBUTIONS}

HLG drafted the manuscript; JV, JJD and CDB participated in the writing and editing of the manuscript; CDB prepared and approved the final manuscript. 


\section{Introduction}

Worldwide, the leading causes of infant mortality are congenital abnormalities, SIDS, prematurity and low birth weight [1]. The concept of SIDS was defined in 1969 as "the sudden death of any infant or young child, which is unexpected by history, and in which a thorough post-mortem examination fails to demonstrate an adequate cause for death". The definition was revised in 1989 as "the sudden death of an infant under one year of age, which remains unexplained after a thorough case investigation, including performance of a complete autopsy, examination of the death scene, and review of the clinical history". This definition included an accompanying statement; "cases failing to meet the standards of this definition, including those without a post-mortem investigation, should not be diagnosed as SIDS" [2].

The aim of medico-legal investigations is to provide sufficient evidence to explain the cause of death. SIDS is a subcategory of SUDI and can only be diagnosed after medico-legal investigations exhausted all other causes of death [3]. After years of international research, attempts to identify and confirm the cause of death for some SUDI cases are still unsuccessful, leaving SIDS a medical mystery [4]. Data on South African SUDI and SIDS cases is limited [5] and a question in desperate need of an answer, specifically in terms of infectious investigations, is what constitutes a complete and thorough SUDI medico-legal autopsy in South Africa [4]?

\section{Medico-legal investigation into SUDI and SIDS}

Currently, SUDI cases in South Africa are admitted to the FPS Mortuaries for investigation under the auspices of the country's Inquests Act (58 of 1959). No standard national guidelines exist for examination of these cases [6]. The need for standard national and international protocols to streamline SUDI investigations and facilitate research has been clearly acknowledged internationally $[7,8]$ and in South Africa $[5,6]$. 
Du Toit-Prinsloo et al. [5] reviewed SUDI case files from 2000 to 2004 at Tygerberg FPS Mortuary in the Western Cape and Pretoria FPS Mortuary in Gauteng, South Africa. They found discrepancies between SUDI investigation procedures that could affect the profiles of the final diagnostic categories for infant death. In particular, Tygerberg FPS Mortuary conducted viral and bacterial investigations in $60 \%$ of cases, compared to Pretoria FPS Mortuary where viral investigations were performed in only 3\% of cases. Macroscopic autopsies and histological analysis were also performed for more SUDI cases at Tygerberg FPS Mortuary [5]. Tygerberg FPS Mortuary may currently be one of the few academic institutions in South Africa where SUDI cases are more extensively investigated.

Cases admitted to Tygerberg FPS Mortuary are investigated according to a standard facility protocol. This includes case note review, autopsy and laboratory investigations. All SUDI cases are subjected to a routine viral culture screen by the National Health Laboratory Service for human adenovirus (HAdV), cytomegalovirus (CMV), influenza A and B, human parainfluenza virus (HPIV) 1, 2 and 3, human metapneumovirus (HMPV) and respiratory syncytial virus (RSV) from lung and liver tissues. Viral culture is rarely successful from autopsy specimens. Numerous other respiratory viruses have been isolated from SUDI cases and new respiratory viruses are continuously being discovered [8-11]. This justifies the need for nucleic acid (NA) amplification techniques that are continually improved to maintain the changing virological profile that could contribute to SUDI [8]. Rambaud et al. [12] emphasised that bacterial and viral testing in SUDI investigations are important and that a diagnosis of SIDS should be regarded as invalid if no such tests were conducted. The presence of viral pathogens in lung tissue from SIDS cases is not always indicative of cause of death, for example dormant CMV has been found in numerous infants and babies without any pathological manifestation [11]. Fodha et al. [13] found that high nasopharyngeal RSV viral loads were shown to be a strong predictor of disease severity in infants, but a specific 
viral load that is required for respiratory infections to be deemed a significant contributing factor in causing death is still undefined [14]. Weber \& Sebire [15] suggested investigating the systemic responses to pathogens isolated instead of relying only on detection. This would give a better idea of the role pathogens play in disease progression.

\section{The burden of respiratory disease}

Acute respiratory infection is the leading cause of childhood morbidity and mortality worldwide. In 2008 the reported number of worldwide deaths between infancy and early childhood was 8795 million, of which 5970 million (68\%) were due to infectious causes, with the majority due to pneumonia [16]. Pulmonary infections have commonly been diagnosed as a cause of death upon completion of investigations for SUDI cases $[6,7,17]$.

Many respiratory viruses show definite seasonal variation, such as RSV [18], HMPV, influenza [19] and PIV, with peaks during winter [20]. A rise in SIDS cases has been documented in certain populations where infections are frequent, including during colder climates and annual influenza outbreaks [21,22,23].

\section{Viral pathogens in SUDI and SIDS cases}

Some viruses isolated from SUDI cases include human enterovirus [10,23], HAdV [10,23,24], Epstein-Barr virus (EBV) [10,11], parvovirus B19 [10], human herpes simplex virus (HSV) [10,11], CMV [11,23,24], human rhinovirus (HRV) [24], influenza virus [23,24], RSV [23,25], HPIV [25] and rotavirus [26], isolated from myocardial, lung, bowel and liver specimens $[10,23,24]$. At Tygerberg FPS Mortuary myocardial and bowel specimens from SUDI cases are not considered for routine viral investigation and HRV, EBV, parvovirus B19, HSV, human enterovirus and rotavirus do not grow in shell-vial cultures. 
The significance of detecting viruses has largely remained undetermined in the context of SIDS [10,11,24,27]. Controversy exists and the same viruses are circulating at similar or higher frequencies in babies that died from accidents, and are also similar to those viruses circulating in living babies and infants in the general population causing self-limiting infections [27,28]. In support of an infectious aetiology Rambaud et al. [12] conducted a study in France between 1994-1998 where it was found that 62\% of the SUDI cases displayed clinical symptoms of rhinitis and coughing prior to death. Weber et al. [7] found a definite cause of death in about $37 \%$ of SUDI cases after autopsies were performed in the UK between 1995 and 2005. Of these deaths, $58 \%$ were due to infections, with $22 \%$ caused by pneumonia.

Factors that influence the yield of viral detection in SUDI include optimal sampling, selection of viruses tested, selection of optimal methods to be used and interpretation of significance of positive viral results. Extended death to post-mortem intervals may affect virus viability and viral NA integrity, which could result in reduced viral detection during culture attempts and molecular assays [23]. There is currently no defined window period to ensure the successful detection of viruses in molecular or culture assays, but Rambaud et al. [12] showed that a post-mortem interval of up to four days still yielded significant bacterial and viral isolates in $85 \%$ of SUDI cases using molecular detection methods.

The pathogenicity of respiratory viruses can be low in immunocompetent individuals and is often associated with a good prognosis, but infants succumbing to SIDS have been suggested to be neither completely healthy, nor have normal defence mechanisms. Some may have underlying genetic and biological vulnerabilities which can predispose them to SIDS [15]. Coxsackievirus B and HAdV had been shown to be the most frequently identified viral pathogens in infections of the heart, while HAdV had also been implicated in infections of 
the respiratory and gastrointestinal tracts and it is therefore suggested in the literature that downregulation of the viral receptors at or shortly after birth may be the key factor [29,30].

A critical approach to SIDS was developed in the $20^{\text {th }}$ century which described the syndrome as a result of multiple predisposing factors, external stresses and underlying vulnerabilities [31]. This approach gave rise to the triple-risk model, where the risk is highest when an underlying vulnerability in homeostatic control and an exogenous stressor coincide at a critical developmental stage $[23,32,33,34]$. The most likely environmental or exogenous trigger is a viral infection and the proposed underlying vulnerabilities include immune deficiencies and poor control or over-expression of inflammatory mediators [15,23,33]. Viral infections may act in combination with the immune response of the host to infection and the initiation of bacterial toxin production, thereby contributing to SIDS. Viruses also enhance cytokine activity, leading to unregulated expression of inflammatory mediators $[22,35,36]$.

\section{Functional immaturity of the infant immune system and the peak period for SIDS}

The immune system of infants is functionally immature. Before birth, the sterile uterine environment offers little antigen exposure [37]. In the neonatal period infants are dependent on their innate immune mechanisms for protection against pathogens and rely on maternally transferred antibodies for limited adaptive immune protection. This offers some protection against infectious disease, but impaired responses in a substantial number of infants lead to susceptibility to disease. Antibody responses in infants are typically shorter, delayed and respond with lower immunoglobulin (Ig) G2 expression with lower affinity to specific antigens than those found in adults $[37,38]$.

Fewer neutrophils are present in babies and their neutrophils and monocytes also respond sub-optimally to chemo-attractants [37]. Between birth and 1 month, monocytes from infants generate less interferon (IFN)- $\alpha$, IFN- $\gamma$ and interleukin (IL)-12p70 than adults, although 
production increases rapidly from birth to 2 years of age. Early infancy is further marked by low numbers of effector memory B cells $\left(\mathrm{CD} 27^{+}\right)$and effector memory $\mathrm{T}$ cells $\left(\mathrm{CD} 45 \mathrm{RA}^{-}\right.$ $\left.\mathrm{CD} 45 \mathrm{RO}^{+}\right)$. Although cytokines in infants seem to be less polyfunctional than in adults, they are key components in the regulation of innate and adaptive immune responses to viral infections through interference with viral entry and replication [37,38,39].

Infants are capable of mounting a T cell response to infectious agents, but it differs in quality and magnitude compared to adults. Infant $\mathrm{CD}^{+} \mathrm{T}$ cell responses take longer to develop upon intracellular primary infection with CMV and HSV [38]. Cytokines in neonates are initially expressed by naïve memory $\mathrm{T}$ cells, predominantly producing IL-2, but maturing over time to effector T cells, producing IFN- $\gamma$ and tumour necrosis factor (TNF)- $\alpha$ [40].

B cells from neonates express less cell surface receptors (CD21, CD40, CD80 and CD86) and also show defects in germinal center formation. These defects only resolve by four months of age, which may contribute to the two to four month peak window period for SUDI [38]. Immature immune responses could therefore be involved in events leading to SUDI. Immaturities of the innate immune system that direct adaptive immune response functioning, leave infants vulnerable to developing infections [37,41].

Exposure to cigarette smoke, poor nutrition, a mild viral infection, excessive heat while sleeping in the prone position, an immature immune system due to a critical period in development and other medical conditions all pose enough risk factors to fit the triple-risk model for SIDS $[15,23,33,34]$. Since SIDS is documented to be higher in the two to four month age group, this could represent a critical developmental period that coincides with a loss of immune protection due to of waning maternally transferred antibodies $[5,42]$. Placental transfer of IgG provides specific immune protection in infants during the early weeks of life [43]. The benefits are short-lived and only limited protection is conferred [42]. 
Mothers infected with the human immunodeficiency virus (HIV) $[45,46]$ or with vaccineinduced immunity [47] transfer lower levels of maternal IgG antibodies for specific vaccine preventable infections to their infants.

Due to the functionally immature immune system infants respond differently to infections, compared to older children and adults. Signs of clinical progression of illness may not be prominent [48]. All babies start off with a functionally immature immune system, but not all babies are predisposed to SUDI. The suggestion that certain clinical symptoms may be missed in some infants may be what sets healthy infants apart from those predisposed to SUDI, especially when a subset of infants are additionally exposed to external risk factors (i.e. excessive wrapping, cigarette smoke and sleeping in the prone position), and have pathophysiological abnormalities. In these instances, and in line with the triple-risk model, the functionally immature immune system could contribute by increasing infant vulnerability to viral infections.

\section{Inflammation and possible contributions to infant demise}

To establish a definite cause of death in SUDI cases can be challenging when minor signs of inflammation are present and where boundaries between normal pathology and a subtle disease state can be indistinguishable. Krous et al. [14] acknowledged that histological evidence of severe myocardial inflammation is easily attributed to myocarditis, but when very mild myocardial inflammation is detected, the significance remains questionable and could even possibly be normal findings when infants are exposed to environmental pathogens. To observe inflammatory infiltrations the appropriate chemo-attractant signals are required to facilitate migration of these cells to sites of infection. The existence of a window period was suggested during which the molecular signals of inflammation may already be evident before manifestations of inflammation can be observed histologically [49]. In infancy 
this window period may further be prolonged, because their neutrophils and monocytes are less sensitive to chemo-attractants [37].

The immune response to respiratory viruses often induces pro-inflammatory mediators, such as IL-1, IL-6, TNF- $\alpha$ and IFN- $\gamma$, which could lead to septic shock if uncontrolled. IL-1 has been shown to induce drowsiness and sleep apnoea in humans and animal models $[22,49]$. Inflammation can also lead to obstruction of bronchioles, impaired breathing and especially in the case of RSV infection, an exaggerated immune response results [49,50]. The antiinflammatory cytokine IL-10 can dampen exaggerated inflammatory responses and prevent cellular damage. Schultz et al. [51] found a significantly lower IL-10 production in infants compared to adults. Infants may thus be less able to compensate for inflammatory responses and more susceptible to the damaging effects of pro-inflammatory cytokines [51]. Mutations causing lower expression of anti-inflammatory cytokines have been detected in some SUDI cases, together with increased pro-inflammatory cytokines [44].

Surprisingly, despite a functionally immature immune system, production of proinflammatory cytokines can be detected very early in life. The pro-inflammatory cytokine IL6 is considered a marker of inflammation and tissue damage. It is the principal cytokine secreted during the acute-phase inflammatory responses to damage in tissues. IL-6 has been found in high levels in some SIDS cases and infants who died of bacterial sepsis and meningitis $[22,35,49]$. The similar levels of IL-6 highlight possible similarities between SUDI cases and deaths due to infections and could support a contributory role of infections and subsequent immune response in causing SUDI. However, the degree of inflammation required for lethality is still uncertain $[33,35,36]$.

Primary immunodeficiencies or other minor genetic variations may also play a role in SUDI. Recurrent respiratory infections have been linked to a defective antibody response to 
polysaccharide antigens, despite normal levels of IgG subclasses. IgA and IgG2 subclass deficiencies often coexist with other immune defects, such as complement (C)2 and C4 deficiencies, and are associated with recurrent susceptibility to infections [52]. These factors can therefore also contribute to the triple-risk model as part of the underlying vulnerabilities.

By the age of one to two years, when unexplained death rates are considered almost negligible [17], the majority of immune responses and mechanisms have matured and are fully functional $[37,40]$. Because these cases are rare after two years of age, the contributory role of the immature immune system in infant deaths is emphasised.

\section{Summary}

The cause of SIDS deaths remains inconclusive, but we agree with Rambaud et al. [12] that a SUDI case should not be classified as SIDS if appropriate laboratory investigations did not accompany the autopsy. To facilitate appropriate laboratory investigations and ensure comparison of research findings, standardised guidelines for SIDS specimen collection during autopsies need to be established. We also support the view of Weber \& Sebire [15] that the systemic response to pathogens isolated need to be investigated and that viral isolates need to be interpreted in conjunction with immunological and histological signs of infection. The evidence of inflammation in SIDS cases and infants dying of infections confirm the role of infections in some of these deaths. The immature immune system in infancy, and its subsequent maturation, specifically only after the two to four month window period for SIDS, strongly suggests an association, especially in the presence of established risk factors for SIDS. The evidence pointing to a clear viral infectious aetiology in some SUDI cases in this review emphasises the need to screen for a wide variety of pathogens to ensure that infections are not missed. This review confirms the need for bigger studies with more cases, a wider selection of anatomical areas to be sampled, including the heart, gastrointestinal tract, liver, 
etc, as well as continuously updating the selection of both RNA and DNA viruses to be investigated. This should be done in parallel with investigating the pathogenesis and immunopathology of SIDS in an effort to provide crucial information in the search for answers pertaining to this elusive syndrome.

\section{References}

1. Goutas N, Konstantinidou MK, Vlachodimitropoulos D, et al. Trends in infant and child mortality. Open Forensic Sci J. 2011;4:1-11.

2. Willinger, M, James LS, Catz C. Defining the sudden infant death syndrome (SIDS): deliberations of an expert panel convened by the National Institute of Child Health and Human Development. Pediatr Pathol. 1991;11(5):677-684.

3. Krous HF. Sudden unexpected death in infancy and the dilemma of defining the sudden infant death syndrome. Curr Pediatr Rev. 2010; 6(1):5-12.

4. Koehler SA. The importance of a forensics investigation of sudden infant death syndrome: recommendations for developing, low and middle income countries. Acta Medica Academica. 2010;39(2):165-174.

5. du Toit-Prinsloo L, Dempers JJ, Wadee SA, Saayman G. The medico-legal investigation of sudden, unexpected and/or unexplained infant deaths in South Africa: where are we--and where are we going? Forensic Sci Med Pathol. 2011;7(1):14-20.

6. du Toit-Prinsloo L, Dempers J, Verster J, et al. Toward a standardized investigation protocol in sudden unexpected deaths in infancy in South Africa: a multicenter study of medico-legal investigation procedures and outcomes. Forensic Sci Med Pathol. 2013;9(3):344-350.

7. Weber MA, Ashworth MT, Risdon RA, Hartley JC, Malone M, Sebire NJ. The role of post-mortem investigations in determining the cause of sudden unexpected death in infancy. Arch Dis Child. 2008;93(12): 1048-1053. 
8. Prtak L, Al-Adnani M, Fenton P, Kudesia G, Cohen MC. Contribution of bacteriology and virology in sudden unexpected death in infancy. Arch Dis Child. 2010;95(5):371376.

9. Lee JH, Chun JK, Kim DS, Park Y, Choi JR, Kim HS. Identification of adenovirus, influenza virus, parainfluenza virus, and respiratory syncytial virus by two kinds of multiplex polymerase chain reaction (PCR) and a shell vial culture in pediatric patients with viral pneumonia. Yonsei Med J. 2010;51(5):761-767.

10. Dettmeyer R, Baasner A, Schlamann M, et al. Role of virus-induced myocardial affections in sudden infant death syndrome: a prospective postmortem study. Pediatr Res. 2004;55(6):947-952.

11. Álvarez-Lafuente R, Aguilera B, Suárez-Mier MP, et al. Detection of human herpesvirus-6, Epstein-Barr virus and cytomegalovirus in formalin-fixed tissues from sudden infant death: a study with quantitative real-time PCR. Forensic Sci Int. 2008;178(2-3):106-111.

12. Rambaud C, Guibert M, Briand E, Grangeot-Keros L, Coulomb-L'Herminé A, Dehan M. Microbiology in sudden infant death syndrome (SIDS) and other childhood deaths. FEMS Immunol Med Microbiol. 1999;25(1-2):59-66.

13. Fodha I, Vabret A, Ghedira L, et al. Respiratory syncytial virus infections in hospitalized infants: association between viral load, virus subgroup, and disease severity. J Med Virol. 2007;79(12):1951-1958.

14. Krous HF, Fernandos C, Masoumi H, et al. Myocardial inflammation, cellular death, and viral detection in sudden infant death caused by SIDS, suffocation, or myocarditis. Pediatr Res. 2009;66(1):17-21.

15. Weber MA, Sebire NJ. Molecular diagnostic techniques in the post-mortem investigation of sudden unexpected infant deaths: current and future applications. Open Pathol J. 2010;4:110-119.

16. Black RE, Cousens S, Johnson HL, et al. Global, regional, and national causes of child mortality in 2008: a systematic analysis. Lancet. 2010;375(9730):1969-1987. 
17. Côté A. Investigating sudden unexpected death in infancy and early childhood. Paediatr Respir Rev. 2010;11(4):219-225.

18. Kwofie TB, Anane YA, Nkrumah B, Annan A, Nguah SB, Owusu M. Respiratory viruses in children hospitalized for acute lower respiratory tract infection in Ghana. Virol J. 2012;9:78. doi: 10.1186/1743-422X-9-78.

19. O’Callaghan-Gordo C, Díez-Padrisa N, Abacassamo F, et al. Viral acute respiratory infections among infants visited in a rural hospital of southern Mozambique. Trop Med Int Health. 2011;16(9):1054-1060.

20. Smuts HE, Workman LJ, Zar HJ. Human rhinovirus infection in young African children with acute wheezing. BMC Infect Dis. 2011;11:65. doi: 10.1186/1471-2334$11-65$.

21. Nelson KE, Greenberg MA, Mufson MA, Moses VK. The sudden infant death syndrome and epidemic viral disease. Am J Epidemiol.1975;101(5):423-430.

22. Blood-Siegfried J. Sudden infant death syndrome: a toxic response. AACN Clin Issues. 2000;11(2):300-308.

23. Weber MA, Hartley JC, Ashworth MT, Malone M, Sebire NJ. Virological investigations in sudden unexpected deaths in infancy (SUDI). Forensic Sci Med Pathol. 2010;6(4):261-267.

24. Bajanowski T, Rolf B, Jorch G, Brinkmann B. Detection of RNA viruses in sudden infant death (SID). Int J Legal Med. 2003;117(4):237-240.

25. An SF, Gould S, Keeling JW, Fleming KA. Role of respiratory viral infection in SIDS: detection of viral nucleic acid by in situ hybridization. J Pathol. 1993;171(4):271-278.

26. Yolken R, Murphy M. Sudden infant death syndrome associated with rotavirus infection. J Med Virol. 1982;10(4):291-296.

27. Williams AL, Uren EC, Bretherton L. Respiratory viruses and sudden infant death. $\mathrm{Br}$ Med J (Clin Res Ed). 1984;288(6429):1491-1493. 
28. Urquhart GE, Grist NR. Virological studies of sudden, unexplained infant deaths in Glasgow 1967-70. J Clin Pathol. 1972;25(5):443-446.

29. Badorff C, Berkly N, Mehrotra S, Talhouk JW, Rhoads RE, Knowlton KU. Enteroviral protease 2A directly cleaves dystrophin and is inhibited by a dystrophin-based substrate analogue. J Biol Chem. 2000;275(15):11191-11197.

30. Bergelson JM, Cunningham JA, Droguett G, et al. Isolation ov a common receptor for Coxsackie B viruses and adenoviruses 2 and 5. Science 1997;275:1320-1323.

31. Byard RW, Krous HF. Sudden infant death syndrome: overview and update. Pediatr Dev Pathol. 2003;6(2):112-127.

32. Filiano JJ, Kinney HC. A perspective on neuropathologic findings in victims of the sudden infant death syndrome: the Triple-Risk Model. Biol Neonate. 1994;65(34):194-197.

33. Samuels, M. Viruses and sudden infant death. Paediatr Respir Rev. 2003;4(3):178-183.

34. Bajanowski T, Vege A, Byard RW, et al. Sudden infant death syndrome (SIDS)standardised investigations and classification: recommendations. Forensic Sci Int. 2007;165(2-3):129-143.

35. Blackwell CC, Moscovis SM, Gordon AE, et al. Cytokine responses and sudden infant death syndrome: genetic, developmental, and environmental risk factors. J Leukoc Biol. 2005;78(6):1242-1254.

36. Highet AR. An infectious aetiology of sudden infant death syndrome. J Appl Microbiol. 2008;105(3):625-635.

37. Palmeira P, Quinello C, Silveira-Lessa AL, Zago CA, Carneiro-Sampaio M. IgG placental transfer in healthy and pathological pregnancies. Clin Dev Immunol. 2012;2012:985646. doi: 10.1155/2012/985646.

38. PrabhuDas M, Adkins B, Gans H, et al. Challenges in infant immunity: implications for responses to infection and vaccination. Nat Immunol. 2011;12(3):189-194. 
39. Schroder K, Hertzog PJ, Ravasi T, Hume DA. Interferon- $\gamma$ : an overview of signals, mechanisms and functions. J Leukoc Biol. 2004;75(2):163-189.

40. Wiegering V, Eyrich M, Wunder C, Günther H, Schlegel PG, Winkler B. Age-related changes in intracellular cytokine expression in healthy children. Eur Cytokine Netw. 2009;20(2):75-80.

41. Reikie BA, Adams RC, Ruck CE, et al. Ontogeny of toll-like receptor mediated cytokine responses of South African infants throughout the first year of life. PLoS ONE. 2012;7(9):e44763. doi: 10.1371/journal.pone.0044763.

42. Balduzzi PC, Greendyke RM. Sudden unexpected death in infancy and viral infection. Pediatrics. 1966;38(2):201-206.

43. Cáceres VM, Strebel PM, Sutter RW. Factors determining prevalence of maternal antibody to measles virus throughout infancy: a review. Clin Infect Dis. 2000;31(1):110-119.

44. Staines DR. Postulated vasoactive neuropeptide autoimmunity in fatigue-related conditions: a brief review and hypothesis. Clin Dev Immunol. 2006;13(1):25-39.

45. Farquhar C, Nduati R, Haigwood N, et al. High maternal HIV-1 viral load during pregnancy is associated with reduced placental transfer of measles IgG antibody. $J$ Acquir Immune Defic Syndr. 2005;40(4):494-497.

46. Reikie BA, Naidoo S, Ruck CE, et al. Antibody responses to vaccination among South African HIV-exposed and unexposed uninfected infants during the first 2 years of life. Clin Vaccine Immunol. 2013;20(1):33-8.

47. Zhao H, Lu PS, Hu Y, Wu Q, Yao W, Zhou YH. Low titers of measles antibody in mothers whose infants suffered from measles before eligible age for measles vaccination. Virol J. 2010;7:87 doi: 10.1186/1743-422X-7-87.

48. Dempers J, Sens MA, Wadee SA, et al. Progressive primary pulmonary tuberculosis presenting as the sudden unexpected death in infancy: a case report. Forensic Sci Int. 2011;206(1-3):e27-e30. 
49. Gotsch F, Romero R, Kusanovic JP, et al. The fetal inflammatory response syndrome. Clin Obstet Gynecol. 2007;50(3):652-683.

50. Openshaw PJ. Antiviral immune responses and lung inflammation after respiratory syncytial virus infection. Proc Am Thorac Soc. 2005; 2(2):121-125.

51. Schultz C, Temming P, Bucsky P, Göpel W, Strunk T, Härtel C. Immature antiinflammatory response in neonates. Clin Exp Immunol. 2004;135(1):130-136.

52. Bossuyt X, Moens L, Van Hoeyveld E, et al. Coexistence of (partial) immune defects and risk of recurrent infections. Clin Chem. 2007;53(1):124-130. 